\title{
INFLUÊNCIA DE DIFERENTES SISTEMAS DE CULTIVO SOBRE A PRODUÇÃO DE ALFACE DE PRIMAVERA/VERÃO
}

\author{
Luiz Fernando Favarato ${ }^{1}$ \\ Rogerio Carvalho Guarçoni ${ }^{2}$ \\ Ana Paula Siqueira ${ }^{3}$ \\ Jacimar Luis de Souza ${ }^{4}$ \\ André Ângelo Bellon ${ }^{5}$ \\ Gabryele Silva Ramos ${ }^{6}$ \\ Naji Augusto de Souza Ribeiro ${ }^{7}$
}

Resumo: Devido às características climáticas das principais regiões produtoras de alface e com a maior parte dos cultivos feitos em campo aberto, tem sido frequente a incidência de doenças na cultura. Em consequência, ocorre a redução da produtividade e perda de qualidade do produto comercializado, além do problema de resíduos de agrotóxicos, devido ao seu uso abusivo para o controle de pragas e doenças. Dessa forma, o estudo de novas tecnologias, como o cultivo da alface sob túnel baixo torna-se importante, visando o aprimoramento de seu sistema de cultivo. Neste sentido, objetivou-se avaliar a influência de diferentes sistemas de cultivo no desempenho produtivo da alface de primavera/verão. Foram avaliadas as caracteríssiticas de massa da matéria freca e seca de três cultivares de alface (lisa, crespa e americana) em três sistema de cultivo, túnel baixo, muching e convencional. O uso mulching preto com ou sem túnel baixo sobre os canteiros proporcionaram maior desempenho produtivo do cultivar de alface americana no cultivo de primavera/verão.

Palavras-chave: Lactuca sativa L., mulching, ambiente protegido

\footnotetext{
1 Pesquisador/Instituto Capixaba de Pesquisa, Assistência Técnica e Extensão Rural, Brasil. E-mail: Iffavarato@gmail.com.

2 Pesquisador/Instituto Capixaba de Pesquisa, Assistência Técnica e Extensão Rural, Brasil. E-mail: rogerio.guarconi@gmail.com.

3 Extensionista/Instituto Capixaba de Pesquisa, Assistência Técnica e Extensão Rural, Brasil. E-mail: anaposiqueira@gmail.com.

4 Pesquisador/Instituto Capixaba de Pesquisa, Assistência Técnica e Extensão Rural, Brasil. E-mail: jacimarsouza@yahoo.com.br.

${ }^{5}$ Assistente de laboratório/Instituto Capixaba de Pesquisa, Assistência Técnica e Extensão Rural, Brasil. E-mail: aa-bellon@hotmail.com.

${ }^{6}$ Agronomia/Universidade Federal de Viçosa, Brasil. E-mail: gabryele.ramos@ufv.br.

${ }^{7}$ Agronomia/Universidade Federal de Viçosa, Brasil. E-mail: naji.ribeiro@ufv.br.
} 